\title{
LATENT STRUCTURE OF MOTOR ABILITIES \\ AND SKILLS OF DEAF CHILDREN
}

\section{Husnija Hasanbegović ${ }^{1}$ \\ Senad Mehmedinović \\ Esad H. Mahmutović}

Faculty of Education and Rehabilitation, University of Tuzla

Institute for Human Rehabilitation

Center for Education and Rehabilitation of hearing and speech, Tuzla

Received: 25.03.2012

UDC: 159.943-056.263-053.2

Accepted: 14.04 .2012

\begin{abstract}
In this work surveys of latent motility abilities and skills of school children are shown. The sample for this survey was consisted of two subsamples. First one has consisted of deaf children $N=29$, and the second one has consisted hearing children of same age $N=69$. Subsamples of deaf is chosen according to model of applied sample, and subsample is chosen randomly, so two stages group sample $N=90$ has been created. After quantitative differences have been discovered between subsamples, hearing pupils have shown statistically better results at motility skills and techniques than deaf children and cumulative results have been subjected to inter correlation of variables. The target of using this method was determination of saturation of common variability through saturation of variables and their correlation by Ortoblique rotation for determination of latent information that are going to serve as practical guides at education and deaf children treatment, because of improvement of their motility abilities and skills according to hearing children.

Three factors have been singled out as main preview of measurement on manifest variables. According to first review of measuring it has been established that at deaf children is needed to work on improving of physical abilities and mobility and then developed motility abilities and skills. Their information has been gained most probably by non system fluctuations as information about ability of balance maintaining which is most probably non dependable of motility abilities and skills as at deaf and hearing children too. According to this survey by entering the structure of measuring instrument it is possible to create programs for improving motility abilities and skills at deaf children.
\end{abstract}

Key words: mobility of limbs, speed and agility, functional and explosive power.

1 Correspodence to:

Husnija Hasanbegović, Faculty of Education and Rehabilitation, University of Tuzla

Branilaca Banovića 76. Banovići, B\&H

Phone: +387 61739089

E-mail: husnijamaj@hotmail.com 


\section{INTRODUCTION}

Motility skills can be defined as level of adopted motilityknowledge, whichenableestablishingbetter body control, and as such, they accomplish complex actions and enable waking up and development of psychological structures and functions. As per skills qualification system of movement, suggested by Burton (1998), fundamental motility skills are related to specialized and context related motions. Clark 1994, as per Ulrich, 2005, sees fundamental motility skills as basic coordination model, which lies in ability of motion in later years. Evaluation of motility skills of surmounting or un-surmounting of specific motor components, can help in designing the program.

Aim of the research: Determining latent structure of manifest variables of motored abilities and skills of deaf children.

Hypothesis: There are relations and relationships in the system of applicable variables, which can be factors as determinants of causal connection of development of motility abilities and skills.

\section{WORK METHODS}

\section{The examinee sample}

The examinee sample $(\mathrm{N}=98)$ was made of two subsamples of primary school educated deaf and hearing children. First subsample is formed of deaf children, who are included in educational rehabilitation treatment at Centre for Education and Rehabilitation of hearing impaired children in Tuzla $(\mathrm{N}=29)$. Second subsample is formed of hearing children, same chronological age, chosen by method of random selection in four schools in area of Tuzla Canton $(\mathrm{N}=69)$.

\section{Measuring instrument and way of conducting research}

A measuring instrument was formed for the aim of research with name "Test for evaluation of anthropological characteristics (mobility of the extremities) motored abilities and skills" (TAMV). TAMV consists of 3 sub tests. First subtest "Evaluation of motored skills" consists of following variables: object manipulation (number of bounced tennis balls of the racket as per unit of time); object manipulation speed (time of max 30 seconds which was needed for bouncing of the ball by racket), ball manipulation by subordinate arm (number of bounced balls of the ground); ball manipulation by dominant arm and with both arms (number of caught balls bounced of the wall as per unit of time); speed of ball manipulation by dominant arm and by both arms (time of maximum 30 seconds which was needed for catching the ball); specific ball manipulation by subordinate arm (number of caught balls bounced of the ground and wall of 10 attempts) and rolling precision (number of successfully hit targets by rolling the ball of 10 attempts).

Second subtest "Evaluation of motored abilities (EURO FIT)" consists of evaluations: speed and mobility (time necessary for performing 5 complete running cycles); explosive strength (long jump from a standing position); functional strength (static endurance of arms and shoulders' muscles); flexibility of bottom extremities (arms maximum reach from sitting position) and general balance (number of attempts needed to keep balance for a full minute). Third subtest "Evaluation of complex motored abilities and skills" consists of evaluation of situational motored abilities (speed, mobility, balance, agility, coordination and precision). 


\section{Methods of data processing}

Examination data are processed with method of parametric and non-parametric statistics. For statistic data processing a computer statistic program SPSS for WINDOWS 13.0 was used. For determining of latent space of applicable variables of motored abilities and skills, a method of factor analysis was used.

\section{RESULTS AND DISCUSSION}

\section{Latent structure of motored abilities and skills}

Latent structure is determined by model of main components with application of Guttman-Kaiser criteria for determining important main components. Diamond rotation of main components, as per Oblimin criteria, Orthoblique solution, latent dimensions are isolated for whole set of examinees. KMO and Bartletts Test (Kaiser-Meyer-Olkin) is done which represents measure of representative sample of set of manifest variables, by which a relation of real squaring correlations and squaring partial correlations was obtained. On basis of obtained correlation coefficient 0,87 , it is ascertained with reliability $h^{2}=932,12$, that full suitability of set of variables for sub dual to factor analysis exits.

\section{Distinctive values of variables}

According to Guttmann - Kaiser criteria, space of manifest variable has reduced itself to 3 latent dimensions - important factors. From table 1 it can be concluded that obtained factors after diamond rotation were of very wide scope and they represent general factors of motored abilities and skills, and rotation has given well defined and easily interpretable factors. First main component as per mentioned criteria of component model carries the most variability (total 47,19\%), and it is most important in defining motored abilities and skills. Second component carries $11,51 \%$, and third component $1,01 \%$ of variability. By analysis of main components it can be noticed that isolated components explain a total of $65,96 \%$ of variance, which shows the fact that isolated components represent quality and quantity characteristics of motored abilities and skills.

Table 1. Distinctive values (Lambda), cumulative variance (percentage of matrix of intercorelation of variables), percentage of common variance

\begin{tabular}{cccc}
\hline Factor & $\boldsymbol{\Lambda}$ & $\mathbf{\%}$ & $\mathbf{C U M \%}$ \\
\hline 1. & 6,60 & 47,19 & 47,19 \\
2. & 1,61 & 11,51 & 58,70 \\
3. & 1,01 & 1,01 & 65,96 \\
\hline
\end{tabular}

\section{Communality of variables}

By insight into communality of variables can be concluded to be very high and moving in continuance of 0,33 for variable "Flexibility of bottom extremities", up to communality of 0,86 for variable "Speed of ball manipulation by subordinate arm". Highest communalities were achieved by this variable together with variable "Ball manipulation by subordinate arm" which communality was 0,80 which is logical, because it includes motored abilities and skills of ball manipulation with help of upper extremities, which confirms the fact that other variables which have high communalities also relate to manipulation of upper extremities. Relatively low communalities have variables "Flexibility of bottom extremities" 
which communality is 0,33 and "Rolling precision" which communality is 0,36 which is also logical because it is a motored abilities and skills of bottom extremities which are not in this evaluation area in firm correlations, but also "Rolling precision" implies evaluation of space elements and space organizing, which is also not in firm correlation with abilities and skills of upper extremities manipulation.

\section{Parallel and orthogonal projections of variables on factors}

Table 2, represents projections of variables on first main measurement component, and it can be noticed that highest projections of variables on isolated factor had eight variables with its very high parallel and orthogonal projections. Highest parallel and orthogonal projections were obtained by variables "specific ball manipulation by subordinate arm" and "functional and explosive strength", and very high orthogonal projections on isolated main component were obtained by variables "object manipulation" and "object manipulation speed", and variable "ball manipulation by dominant arm and with both arms". It can be noticed that one variable has very high and negative projections, and that is variable "speed and mobility", which measured the time which was necessary to run over certain area, so that these negative projections of variables on isolated factor were expected in relation to the structure of isolated variables with high positive projections. This shows that explosive and functional strength can be connected to manipulation of upper and bottom extremities and their speed, and this factor is called Factor of physical abilities and mobility.

Table 2. Isolated first main component of motored abilities and skills

\begin{tabular}{lrr}
\hline \multicolumn{1}{c}{ Variables } & PAP & ORP \\
\hline Specific ball manipulation by subordinated arm & 0,85 & 0,84 \\
Explosive strength & 0,82 & 0,87 \\
Functional strength & 0,79 & 0,74 \\
Speed and mobility & $-0,74$ & $-0,72$ \\
Object manipulation & 0,66 & 0,82 \\
Object manipulation speed & 0,65 & 0,81 \\
Ball manipulation by dominant arm and with both arms & 0,62 & 0,78 \\
Rolling precision & 0,35 & 0,53 \\
\hline
\end{tabular}

In table 3 , on second isolated component of best parallel and orthogonal projection the best variables were obtained by "general balance" which has positive and high parallel and orthogonal projections and "situational motored abilities" which have negative parallel and orthogonal projections.
Considering that testing of abilities of overcoming polygon barrier in this variable is done, and on variable "general balance", on testing of balance on one leg, negative projection of this variable on isolated factor is logical. Considering that in this isolated component is exclusively on motored abilities and skills of body manipulation and bottom extremities, this factor is called Balance factor. 
Table 3. Isolated second main component of motored abilities and skills

\begin{tabular}{|c|c|c|}
\hline Variables & PAP & ORP \\
\hline Situational motored abilities & $-0,85$ & $-0,84$ \\
\hline General balance & 0,77 & 0,79 \\
\hline
\end{tabular}

In table 4, projections of variables on isolated third component of factor structure are shown, and it can be noticed that all variables have positive projections on isolated factor. After separation in matrix set and matrix structure, evident differences in variables projections which are specifically expressed in variable "manipulation speed by dominant arm and with both arms" can be noticed, where orthogonal projections are more expressed than the parallel projections. This situation can be interpreted in a way that all variables are important for factor interpretation, not only variables with highest projections.
Considering that in isolated variables ball manipulation by subordinate arm is preferred, which is in measure space of applied variables used as a test material, so that the sub samples of examinee's can be put into homogenization of measurement system, and by this avoid subjectivity of evaluation and eventual single entity results in samples, this factor includes manipulation of upper extremities with stress on speed of that manipulation. In relation to this distribution of parallel and orthogonal projection of variables on isolated component, with increasing ball manipulation skills, the speed of that manipulation is increased, and this factor is called Factor of motored skills.

Table 4. Isolated third main component of motored abilities and skills

\begin{tabular}{lcc}
\hline \multicolumn{1}{c}{ Variables } & PAP & ORP \\
\hline Ball manipulation speed by subordinate arm & 0,93 & 0,92 \\
Ball manipulation by subordinate arm & 0,84 & 0,89 \\
Botton extremities flexibility & 0,59 & 0,57 \\
Speed manipulation by dominant arm and with both arms & 0,50 & 0,71 \\
\hline
\end{tabular}

Final research control of latent structure of motored abilities and skills is done on basis of examination of intercorelation factor. By insight into table 5, correlations between first and third isolated factor can be noticed and they are expected, considering the object of this research, because first factor carries title "Factor of physical abilities and mobility", and third factor "Factor of motored skills", which points out to the fact that, by increasing physical abilities and mobility, motored skills with children from applied sample of this research are increased. Second factor has no positive correlation with other two factors, even very low and negative correlations can be notices, which points out to the fact that "Balance factor" can be administered to some other skills and specific characteristics, which do not belong or in small part belong to motored abilities and skills. 
Table 5. Correlation of isolated factors

\begin{tabular}{ccrr}
\hline Component & $\mathbf{1}$ & $\mathbf{2}$ & \multicolumn{1}{c}{$\mathbf{3}$} \\
\hline 1 & 1,00 & $-0,08$ & 0,56 \\
2 & $-0,08$ & 1,00 & $-0,09$ \\
3 & 0,56 & $-0,09$ & 1,00 \\
\hline
\end{tabular}

\section{CONCLUSION}

By factor analysis, three factors are separated as main overviews of measurement on manifest variables, and it is concluded that on first main overview measurement factor "Factor of physical abilities and mobility" is isolated, which is determined by eight key variables in motored abilities, and factor "Factor of motored skills", as factor which is related to the first overview measurement, and on this way gives guidelines to omissions which were and are made with population of deaf children. Also, it is concluded that "Balance factor" is independent of motored abilities and skills and that it can be administered to some other abilities. This research are led by research results (Effgen, 1981), which noticed that there are no statistic important differences in static balance between deaf and hearing children and Wiegersma and Velde (1983, pp. 103-111), which noticed that deaf children are relatively slower in relation to hearing children, and Rine et.al. (2004, pp. 1141-1148) which have as per EURO FIT standard test for children aged between 6 and 18 years, received low level of strength and endurance of deaf children in relation to hearing children, where as main cause of weak results, state lack of motivation for psychical activities. Research results have caused conclusion that deafness considerably influences the level of coordination ability.

\section{REFERENCES}

- Burton, A.W. (1998). Movement skill assessment. Champaign, IL: Human Kinetics.

- Clark, J.E. (1994). Motor development. In V.S. Ramachandran (Ed.). San Diego: Academic Press.

- Effgen, S.K. (1981). Effect of an Exercise Program on the Static Balance of Deaf Children. Georgia State University: Atlanta. Vol. 61, No. 6.

- Rine, R.M., Braswell, J., Fisher, D., Joyce, K., Kalar, K. and Shaffer, M. (2004). Improvement of motor development and postural control following intervention in children with sensorineural hearing loss and vestibular impairment. International Journal of Pediatric Otorhinolaringology. Vol 68.

- Ulrich, A. (2005). Test of Gross Motor Development. Second Edition. TX: PRO-ED.

- Wiegersma, P. H. and Velde, A.V. (1983). Motor development of deaf children. Department of developmental psychology: The Netherlands, Vol 24(1). 